\title{
The challenge in developing in mathematics teachers an inquiry stance to teaching
}

\author{
Peter Sullivan
}

Published online: 30 April 2010

(C) Springer Science+Business Media B.V. 2010

My main reaction as I reread the articles in this issue of the Journal of Mathematics Teacher Education while preparing to write this editorial was to reflect on the teacher education program in which I teach.

I teach in a 1-year postgraduate program for prospective secondary teachers (who will teach students aged 12-18), which consists of a collection of units (courses) addressing various aspects of learning to teach. The mathematics education is covered in what we call "methods". There are four core units that are intended to address some issues common to the preparation of all teachers whatever their specialization. I teach one of these termed, simply, "Productive classrooms". I do recognize the irony in delivering a lecture to 300 students, the main focus of which is group learning. In my defence, the prospective teachers also have small tutorials in which I plan group learning activities including assigning specific roles to group members and having tutors simulate assessing the respective groups on their products. The hope is that the lecture will provide some perspectives on the purposes and practices of group learning and that the experience in the tutorial will alert the prospective teachers to the potential of group learning as a useful pedagogical approach. This structure is based loosely on a constructivist perspective, with the tutorial experiences seen as the key to interpreting the information presented in the large group lectures. I have a similar sense of discomfort and irony in the lecture delivered on the topic of constructivist approaches, even though this too is supported by tutorials that include structured experiences intended to enhance awareness of the power of constructivist approaches to teaching, whatever their specialist subject.

I have a lingering uncertainty about the impact of this overall approach. Just recently, I delivered a carefully prepared lecture on approaches to classroom management, included in which I posed the following scenario: "A year seven girl (aged 12) comes to you in the schoolyard to tell you that some year nine boys have stolen her tennis ball. What do you do?" The lecture focuses on three different approaches (Restorative justice is perhaps the best known of these), all of which emphasize rights and responsibilities and strategies that can encourage the bullies to recognize the rights of the victims. As with the above

P. Sullivan $(\bowtie)$

Monash University, Clayton, VIC, Australia

e-mail: peter.sullivan@education.monash.edu.au 
examples, there were specific tutorial experiences that emphasized this approach, and an examination of school policies that had been developed within this framework. I have various mechanisms for gathering feedback on the ideas I present, and the following week, I sought responses on how the prospective teachers would seek to respond to the scenario. The majority of the prospective teachers indicated that they did not accept my approach to the schoolyard scenario, arguing that they wanted the year nine boys punished. I suspect that, even supported by thoughtfully delivered lectures and carefully prepared tutorials, the unit is presenting information not knowledge, experience not awareness, random ideas not orientation to inquiry, and suggestions for consideration not commitment to transformative action.

So these four articles in this issue each led me to reflect on aspects of the approach to teacher education in my university.

David Slavit and Tamara Nelson's article "Collaborative teacher inquiry as a tool for building theory on the development and use of rich mathematical tasks" reports on a teacher development initiative in which they engage teachers in collaborative inquiry of aspects of teaching, including focusing on student work samples, arguing that this inquiry approach had an impact on the subsequent practices of these teachers. They particularly emphasized the facilitation processes that support this inquiry.

In another perspective on collaborative inquiry, the article by Othman Nayef Alsawaie and Iman M. Alghazo "The effect of video-based approach on prospective teachers' ability to analyse mathematics teaching" used an experimental and control group approach and found that the experimental group used more sophisticated language to describe teaching after interactive analysis of videotapes of lessons. The inference is that the detailed and collaborative study of practice facilitated via videotaped exemplars is more likely to prompt insight and reflection than are more abstract approaches.

The article by Jo Towers "Learning to teach mathematics through inquiry: A focus on the relationship between describing and enacting inquiry-oriented teaching" argues that there is connection between the stance taken by the approach to learning to teach and the orientation of graduates to adopting similar stances in their own teaching. In other words, if we want teachers to adopt an inquiry approach with their students, then it is helpful if they themselves have learned to teach in this way.

The three articles prompted me to think about ways in which the team of lecturers in my program might find ways to stimulate inquiry-based approaches, even within the financial and organizational constraints within which the program operates.

The fourth article also encouraged me to reflect on my current approach. Like many other recent cross-cultural studies, the article by Jinfa Cai and Tao Wang "Conceptions of effective mathematics teaching within a cultural context: Perspectives from China and the Unites States" allows us to reflect on some key aspects of teaching through the contrast between the perspectives of the teachers from these countries. One of the key findings was that the teachers from both countries saw memorization and understanding as very much linked, which is interesting in that many of the contributions to this and other journals focusing on mathematics teacher education tend to emphasize understanding and pay quite little attention to memorization. Yet, a more striking finding was that US teachers saw memorization as coming after understanding, whereas Chinese teachers saw memorization as coming before understanding. You will have to read the article to determine the meanings the authors and the research participants attribute to those terms, but it seems that even from a constructivist perspective, one of these two perspectives must be better than the other. Even recognizing that there may be some aspects of mathematics for which memorization first might facilitate understanding (learning the names and definitions of 
shapes followed by analysis of the properties of shapes might be one such example) and other aspects for which understanding might facilitate memorization (e.g., connecting the patterns in multiples of nines might facilitate remembering the nine times tables), it seems that logically and even philosophically only one of these approaches can be the right one.

There are two implications from the Cai and Wang article for me. First, like the orientation of my prospective teachers towards punishment, I suspect that many teachers have much stronger beliefs about the importance of memorization than most mathematics teacher educators, and so educators need to find ways to connect with, and build on, the beliefs that the teachers hold. Second, the structure of the unit I teach adopts (loosely) this Chinese approach: information (like memorization) before experience (like understanding). It occurs to me that it may be possible to structure the program so that the tutorial experiences come before the lecture, with the lecture having a more analytical role. I need to make an active decision on which is more likely to prompt engagement with the ideas.

I hope the articles in this issue give you the opportunities to reflect on aspects of your own approach to teacher education, whether you work with practicing or prospective teachers. That indeed is one of the purposes of the journal. 